\title{
PERHITUNGAN KERAPATAN ION NITROGEN PADA PEMBENTUKAN FeN DALAM PROSES NITRIDASI PLASMA
}

\author{
Widdi Usada \\ Pusat Teknologi Akselerator dan Proses Bahan BATAN Yogyakarta \\ Jl Babarsari Kotak Pos 6101 ykbb, Yogyakarta 55281, e-mail :w_usada@yahoo.com
}

Diterima 14 Desember 2010, diterima dalam bentuk perbaikan 6 Januari 2011, disetujui 18 Januari 2011

\begin{abstract}
ABSTRAK
PERHITUNGAN KERAPATAN ION NITROGEN PADA PEMBENTUKAN FeN DALAM PROSES NITRIDASI PLASMA. Telah dilakukan perhitungan kerapatan ion nitrogren pada pembentukan FeN dalam proses nitridasi plasma. Perhitungan menggunakan pengandaian derajat ionisasi dalam plasma $\alpha=10^{-5}$, dan rumusan kekekalan muatan dalam penghitungan cacah partikel ion nitrogen serta teori tumbukan ion nitrogen dengan target $\mathrm{Fe}$ dalam proses pembentukan FeN. Hasil perhitungan menunjukkan bahwa untuk tekanan operasi gas nitrogen dengan jangkau 0,6 sampai 2 torr, maka jangkau kerapatan ion nitrogen adalah 1,6-3,5 $10^{9}$ partikel/cm $\mathrm{cm}^{3}$, dan jangkau rapat daya 0,2 - 1,6 W/cm². Sedangkan untuk pembentukan ikatan FeN, diperoleh cacah dari 0 sampai 1,4 10 ${ }^{5}$, untuk jangkau suhu dari 0 sampai sekitar $610^{4} \mathrm{~K}$
\end{abstract}

Kata kunci : plasma, ion, tumbukan,

\section{ABSTRACT}

THE CALCULATION OF NITROGEN ION DENSITY FOR FeN FORMATION IN PLASMA NITRIDATION PROCESS. The calculation of ion nitrogen density for FeN formation in plasma nitridation process has been done. The calculation was based on the assumption that plasma ionization degree was $10^{-5}$, and using charge conservation rule and particle collision theory for calculating the number of nitrogen ion which collided the target and formation of $\mathrm{FeN}$. Calculation results showed that for the range of nitrogen gas operation pressure from 0.6 to 2 torr, the density of nitrogen ion range was 1.6 to $3.510^{9}$ particles $/ \mathrm{cm}^{3}$, and power density range was 0.2 to $1.6 \mathrm{~W} / \mathrm{cm}^{2}$. Meanwhile for $\mathrm{FeN}$ bonding formation, it was achieved that the range of number particles from 0 to $1.410^{5}$, for temperature range from 0 to $610^{4} \mathrm{~K}$.

Key words : plasma, ion, collision.

\section{PENDAHULUAN}

Salah satu metode untuk mendapatkan komponen mesin industri yang tahan aus dan mempunyai nilai kekerasan yang tinggi adalah dengan metode nitridasi plasma. Nitridasi plasma pada dasarnya adalah pemanfaatan ion nitrogen yang dikenakan pada bahan target, sehingga terjadi ikatan antara nitrogen dengan bahan target. Untuk ikut mendukung penyediaan komponen mesin industri yang unggul tersebut, lembaga ini telah menyusun program kegiatan Rancang Bangun Perangkat Nitridasi Plasma Dengan Double Chamber Untuk Perlakuan Komponen Mesin. Salah satu masalah yang perlu dibahas dalam perancangan sistem tersebut adalah perancangan sistem elektrode khususnya katode yang akan menerima beban tumbukan ion nitrogen berenergi tinggi, sehingga komponen yang diletakkan pada katode akan mengalami proses nitridasi plasma. Untuk mendapatkan perancangan elektrode yang baik diperlukan suatu pemahaman proses interaksi antara ion nitrogen dengan bahan target di elektrode termasuk berapa cacah dan energi ion nitrogen yang berasal dari plasma terbentuk yang berinteraksi dengan target, kemudian kebolehjadian pembentukan ikatan dan lain sebagainya. Perhitungan parameter fisis plasma dengan mendasarkan pada rumusan Paschen untuk perancangan piranti nitridasi plasma telah diperoleh parameter seperti kerapatan plasma, rapat arus dan daya. ${ }^{[1]}$ Namun demikian dalam proses nitridasi plasma untuk pembentukan $\mathrm{FeN}$, masih ada beberapa masalah yang perlu difahami antara lain, kerapatan ion nitrogen, tegangan pemercepat rata-rata, dan kebolehjadian pembentukannya. Sebenarnya tidak hanya proses tersebut di atas yang masih perlu dibahas, namun permasalahan lain seperti disosiasi molekul $\mathrm{N}_{2}$, dan pembentukan ion $\mathrm{N}^{+}$. Untuk memahami masalah-masalah khususnya yang disebutkan di depan, terlebih dahulu perlu difahami proses pelucutan dan karakteristik lucutan plasma, kemudian dicoba dikenalkan teori tumbukan untuk menjelaskan proses dalam nitridasi pada bahan besi. 


\section{DASAR TEORI}

\section{Karakteristik Lucutan Plasma}

Plasma terbentuk setelah ada beda tegangan tertentu sehingga elektron-elektron bebas menumbuk gas dan mengakibatkan terjadinya proses ionisasi gas tersebut. Besarnya tegangan sehingga terjadi ionisasi oleh Paschen dirumuskan sebagai berikut,

$$
\mathrm{V}_{\text {dadal }}=\frac{a(p d)}{\ln (p d)+b}
$$

$V$ dalam volt, $p$ dalam atmosfer, dan $d$ dalam $m$, a adalah tetapan yang direlasikan dengan tenaga ionisasi dan eksitasi gas, sedangkan $b$ adalah tetapan ionisasi jenuh dari gas. Pada umumnya, untuk gas udara besarnya a adalah 365 volt/(cm.torr) dan $b$ sekitar 1,18, sehingga dapat disusun besarnya tegangan dadal untuk berbagai variasi jarak dan tekanan gas.

Secara umum plasma didefinisikan sebagai kumpulan partikel bermuatan seperti elektron, ion bermuatan positif dan ion bermuatan negatif, juga dimungkinkan adanya partikel neutral, dan partikel tereksitasi. Fenomena plasma sedemikian luas spektrumnya baik yang dijumpai dalam kehidupan sehari-hari, di laboratorium, dan juga di industri, bahkan di jagad raya. ${ }^{[2,3,4]}$ Plasma lucutan nyala, merupakan tipe sangat menarik, meskipun hanya bagian kecil dari fenomena plasma. Daya tarik dari lucutan nyala adalah mempunyai karakteristik spesifik yang sangat berguna bagi perkembangan industri seperti plasma sputtering, plasma nitriding, laser, penampil plasma dan lain sebagainya. Karakteristik lucutan antara dua elektrode pelat sejajar ditunjukkan Gambar 1. Dalam penelitian ini hanya beberapa daerah yang sangat berperan saja yang menjadi perhatian dalam pembahasan selanjutnya, yaitu daerah $\mathrm{C}$ dan daerah $\mathrm{F}$. Pada umumnya daerah DEF menjadi satu yang disebut daerah plasma, yaitu besarnya kerapatan ion $n_{i}$ dan kerapatan elektron $n_{e}$ sama. Daerah DEF merupakan daerah pembentukan ion, karena elektron mempunyai tenaga paling tinggi sehingga mampu mendisosiasi molekul dan mengionisasi atom. Untuk proses nitridasi di daerah tersebut terjadi disosiasi molekul $\mathrm{N}_{2}$ menjadi atom nitrogen dan ionisasi dari atom nitrogen menjadi ion nitrogen.

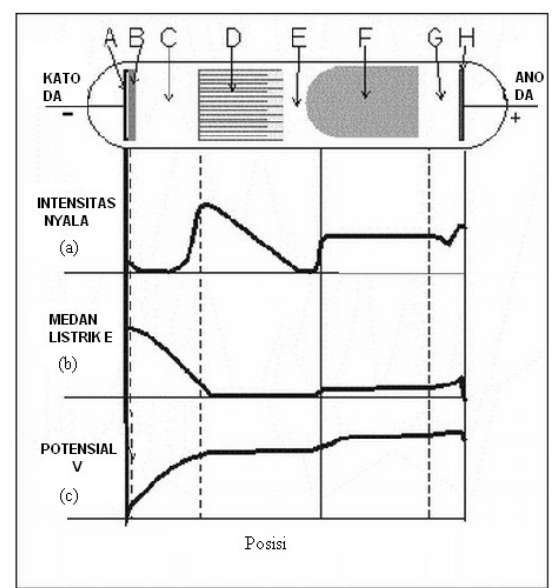

Gambar 1. Distribusi intensitas nyala (a), medan listrik (b) dan potensial (c) pada lucutan nyala.

\section{Daerah Pemercepat Ion dan Elektron}

Intensitas nyala di daerah $C$ hampir dikatakan nol, maka daerah tersebut disebut daerah gelap katode (cathode dark space), namun medan listrik $(E)$ dan potensial listriknya $(V$ justru sangat besar maka daerah tersebut merupakan daerah percepatan terbesar bagi partikel bermuatan positif (ion positif) menuju ke katode, dan percepatan elektron menjauhi katode untuk membentuk proses disosiasi dan ionisasi.

Besarnya tegangan pemercepat daerah $\mathrm{C}$ dapat diperoleh sekitar

$$
V_{C}=V_{A K}-V_{P}
$$


$V_{C}$, adalah tegangan daerah gelap katode, $V_{A K}$ adalah tegangan katode anode dan $V_{P}$ adalah tegangan plasma. $V_{P}$ tegangan yang diperoleh saat arus elektron menunjukkan arus jenuh $\left(l_{\text {ejenuh }}\right)$. Secara umum karakteristik tipikal lucutan plasma ditunjukkan Tabel 1

Tabel 1. Karakteristik tipikal lucutan plasma

\begin{tabular}{|l|c|}
\hline \multicolumn{1}{|c|}{ Besaran } & Kuantitas \\
\hline \hline Tekanan & $0,01-10 \mathrm{Torr}$ \\
\hline Ukuran & $0,1-10 \mathrm{~cm}$ \\
\hline Suhu katode & $300-1000 \mathrm{~K}$ \\
\hline Kerapatan partikel bermuatan & $10^{6}-10^{13} \mathrm{~cm}^{-3}$ \\
\hline Tenaga elektron & $1-4 \mathrm{eV}$ \\
\hline Tenaga ion plasma & $0,01 \mathrm{eV}$ \\
\hline Tenaga ion di katode & $1-1000 \mathrm{eV}$ \\
\hline Derajad ionisasi (a) & $10^{-7}-10^{-4}$ \\
\hline
\end{tabular}

Dengan memahami karakteristik lucutan di atas maka diperoleh fenomena berikut :

1. Di daerah plasma, ion mempunyai energi yang sangat rendah, sehingga ion positif tidak memberikan dampak yang nyata untuk terjadi proses interaksi dengan atom atau molekul lain.

2. Ion memperoleh energi karena adanya tegangan di daerah percepatan, sehingga tumbukan ion dengan target akan mengakibatkan panas, dan kemungkinan terjadi pembentukan ikatan dengan bahan target.

Untuk memperoleh besarnya kerapatan ion yang menuju ke katode, diperlukan persamaan kekekalan muatan yaitu

$$
n_{1} v_{1}=n_{2} v_{2}
$$

$\mathrm{n}_{1}$ adalah kerapatan ion dalam plasma, $\mathrm{v}_{1}$, kecepatan ion dalam plasma, $\mathrm{n}_{2}$ kerapatan ion di katode, dan $\mathrm{v}_{2}$ kecepatan ion di katode.

\section{Tumbukan Partikel ${ }^{[5]}$}

Teori tumbukan yang akan digunakan dalam memahami interaksi partikel dengan mengandaikan bahwa partikel yang bertumbukan berbentuk bola, dan jenis tumbukannya head-on. Gambar 2 menunjukkan tumbukan dengan pengandaiannya, yaitu tumbukan partikel berbentuk bola.

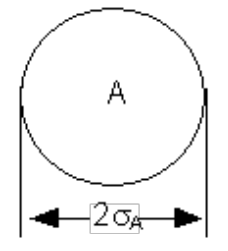

(a)

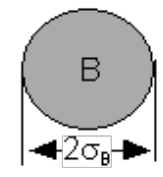

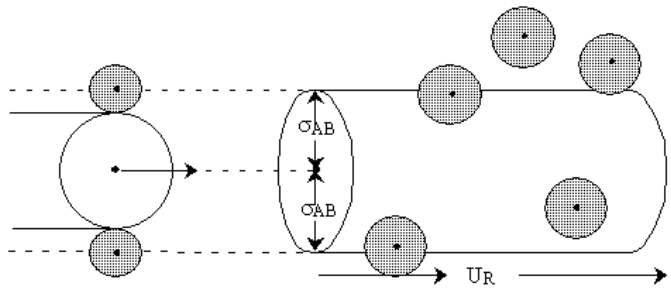

(b)

Gambar 2. Model tumbukan head-on dengan partikel A dan B berbentuk bola

Dengan pengandaian tersebut, maka untuk interaksi partikel $A$ dengan $B$ dapat direlasikan dengan reaksi kedua partikel dan membentuk partikel $C$ dan $D$, yang dituliskan sebagai

$$
A+B \rightarrow C+D
$$

Dengan model di atas, maka dari Gambar 2(a), partikel A mempunyai diameter $2 \sigma_{A}$ dan partikel B mempunyai diameter $2 \sigma_{B}$, jari-jari masing-masing partikel adalah $\sigma_{A}, \sigma_{B}$, Jari-jari tumbukan adalah $\sigma_{A B}$.

$$
\sigma_{A B}=\sigma_{A}+\sigma_{B}
$$

dan tampang lintang tumbukan menjadi 


$$
\mathrm{S}_{\mathrm{r}}=\pi \sigma_{\mathrm{AB}}^{2}
$$

Pengandaian selanjutnya, berdasar Gambar 2(b), maka molekul B dalam keadaan diam, sedangkan molekul $A$ bergerak menuju molekul $B$ dengan kecepatan relatif $U_{R}$. Kecepatan relatif ini didefinisikan sebagai

$$
U_{R}=\left(\frac{8 T k_{B}}{\pi \mu A B}\right)^{1 / 2}
$$

dengan $\mathrm{k}_{\mathrm{B}}=$ tetapan Boltzmann $=1.381 \times 10^{-23} \mathrm{~J} / \mathrm{K} /$ molekul $=1.381 \mathrm{~kg} \mathrm{~m}^{2} / \mathrm{detik}^{2} / \mathrm{K} / \mathrm{molekul}, m_{A}=$ massa molekul gas $A(\mathrm{gm}), m_{B}=$ massa molekul gas $B(\mathrm{gm}), T$ adalah suhu partikel, dan $\mu_{\mathrm{AB}}$ adalah massa tereduksi yang didefinisikan sebagai

$$
\mu_{A B}=\frac{m_{A} m_{B}}{m_{A}+m_{B}}
$$

Dalam beberapa hal sering digunakan satuan mol, maka konstanta dan besaran yang digunakan memuat $\mathrm{M}_{\mathrm{A}}=$ Berat molekul $\mathrm{A}, \mathrm{M}_{\mathrm{B}}=$ Berat molekul $\mathrm{B}, N_{\mathrm{Avo}}=$ Bilangan Avogadro $=6.022 \times 10^{23} \mathrm{molekul} / \mathrm{mol}, R=$ Tetapan gas ideal $=8.314 \mathrm{~J} / \mathrm{mol} / \mathrm{K}=8.314 \mathrm{~kg} \mathrm{~m}^{2} / \mathrm{detik}^{2} / \mathrm{mol} / \mathrm{K}$.

$$
\mathrm{R}=\mathrm{N}_{\mathrm{Avo}} \mathrm{k}_{\mathrm{B}} \text { dan } \mathrm{M}_{\mathrm{A}}=\mathrm{N}_{\mathrm{Avo}} \mathrm{m}_{\mathrm{A}}
$$

sehingga tetapan $\frac{k_{B}}{\mu_{A B}}$ direlasikan dengan

$$
\frac{k_{B}}{\mu_{A B}}=\left[\frac{R}{\frac{m_{A} m_{B}}{m_{A}+m_{B}}}\right]
$$

Rumusan-rumusan di atas digunakan untuk memperoleh besaran-besaran baru yaitu jumlah tumbukan, seluruh partikel $A$ dengan seluruh partikel $B, Z_{A B}$ dengan satuan partikel/detik/ $\mathrm{cm}^{3}$ yang didefinisikan sebagai

$$
\mathrm{Z}_{\mathrm{AB}}=\pi \sigma_{\mathrm{AB}}^{2} \mathrm{U}_{\mathrm{R}} \mathrm{C}_{\mathrm{A}} \mathrm{C}_{\mathrm{B}}
$$

dengan $C_{A}$ konsentrasi partikel $\mathrm{A}$ dan $C_{B}$ konsentrasi partikel $\mathrm{B}$, dan substitusi $U_{R}$, diperoleh relasi ${ }^{[8]}$

$$
Z_{A B}=\pi \sigma_{A B}^{2}\left[\frac{8 k_{B} T}{\pi \mu_{A B}}\right]^{1 / 2} \exp \left(\frac{-E_{a}}{k T}\right) C_{A} C_{B}
$$

Disini telah dimasukkan faktor eksponensial yang menunjukkan bahwa akan terjadi reaksi bila tenaga interaksi antara kedua partikel yang bertumbukan telah melampaui energi aktivasi $E_{a \text {. }}$

\section{PERHITUNGAN, HASIL DAN PEMBAHASAN}

\section{Penentuan Kerapatan Ion Nitrogen di Daerah Katode dan Rapat Daya}

Gambar 3, menunjukkan piranti plasma nitriding dengan material yang dinitridasi serta karakteristik lucutan nyala di sekitar katode, untuk digunakan sebagai penolong dalam membayangkan terjadinya proses pembentukan nitrida besi. Dalam gambar ditunjukkan bahwa material yang dinitridasi diletakkan pada katode, sehingga material yang dinitridasi akan ditumbuki oleh ion nitrogen berenergi tinggi. Pengambilan contoh derajat ionisasi $\alpha=10^{-5}$, karena pada nilai sebesar itu lucutan nyala cukup stabil, bila dibandingan untuk nilai $10^{-7}$ dan $10^{-4}$, karena pada daerah tersebut lucutan nyala tidak stabil. Nilai derajat ionisasi $\alpha=10^{-4}$, merupakan daerah kritis, karena lucutan akan berubah menjadi lucutan busur. Bila lucutan busur muncul maka nilai arus akan sedemikian 
besar, maka efek pemokusan akan muncul, sehingga lucutan hanya terjadi di suatu daerah tertentu saja, oleh karena itu pengaturan tegangan dan tekanan operasi perlu diperhatikan. Efek pemokusan adalah efek yang muncul akibat arus yang besar menimbulkan medan magnet induksi, dan medan magnet induksi ini akan mengakibatkan adanya gaya kompresi radial ke arah dalam, sehingga plasma akan mengecil. Selain efek pemokusan, karena arus sedemikian besar, maka jumlah cacah ion yang menumbuk target akan semakin besar, dan kondisi ini akan mengakibatkan pemanasan target yang sedemikian cepat, padahal berdasarkan eksperimen suhu operasi proses nitridasi plasma tertentu. Pengambilan nilai $\alpha=10^{-7}$, juga merupakan keputusan yang tidak bagus, karena pada lucutan nyala seperti disebutkan di atas menjadi tidak stabil, karena pembentukan ion baru terlalu kecil untuk menopang terjadinya lucutan nyata yang stabil, disamping itu laju arus terlalu kecil sehingga proses pembentukan nitridasi juga akan sangat lama.

$(\text { a })^{[6]}$

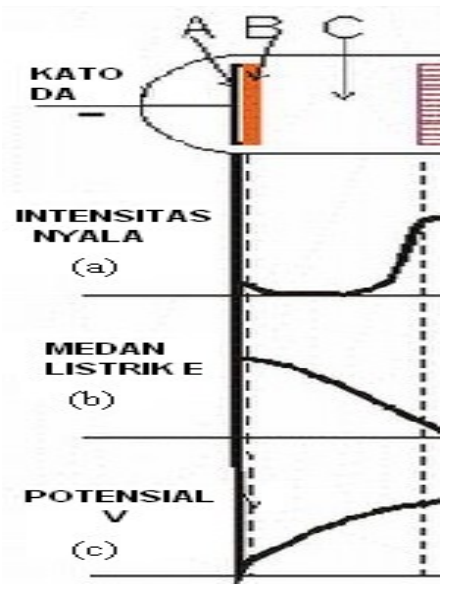

(b)

Gambar 3. Piranti nitridasi plasma dan karakteristik lucutan di sekitar katode

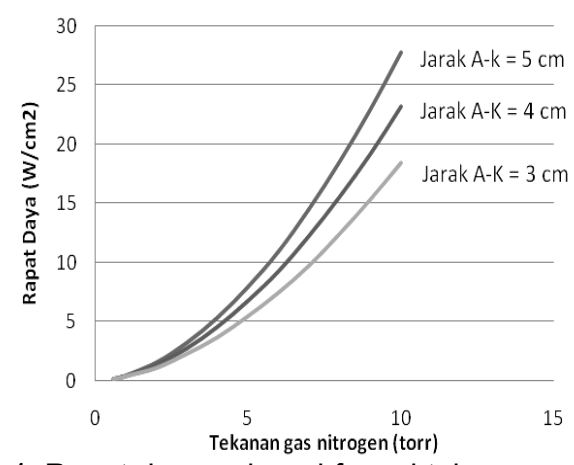

Gambar 4. Rapat daya sebagai fungsi tekanan gas nitrogen

Berdasarkan hasil perhitungan ${ }^{[0]}$ dengan alur perhitungan seperti ditunjukkan pada LAMPIRAN dan dengan menggunakan persamaan (3), serta tegangan rata ion nitrogen adalah $1 / 2 V_{\text {operasi, }}$ maka rapat daya untuk berbagai jarak anode (A) katode (K) sebagai fungsi tekanan diperlihatkan pada Gambar 4. Gambar 4, memperlihatkan bahwa semakin tinggi tekanan operasi, semakin besar pula daya yang dibutuhkan.

Seperti ditunjukkan pada Gambar 4, untuk jarak anode dan katode, semakin jauh, rapat daya yang dibutuhkan juga semakin besar. Hasil perhitungan juga menunjukkan bahwa untuk jangkau tekanan operasi 0,6 sampai dengan 2 torr, rapat daya berkisar dari 0.2 sampai dengan 1,6 W/cm², seperti ditunjukkan Tabel 2. 
Tabel 2. Hasil perhitungan parameter tekanan, kerapatan,rapat arus serta rapat daya untuk jarak katode anode $5 \mathrm{~cm}$

\begin{tabular}{|c|c|c|c|c|c|c|c|c|}
\hline $\begin{array}{c}\mathrm{P} \\
\text { (torr) }\end{array}$ & $\begin{array}{c}P \\
\text { (atm) }\end{array}$ & $\begin{array}{c}\mathrm{No} \\
\left(\mathrm{cm}^{-3}\right)\end{array}$ & $\begin{array}{l}\mathrm{V}_{\text {breakdown }} \\
(\mathrm{V})\end{array}$ & $\begin{array}{l}\text { Vop } \\
\text { (V) }\end{array}$ & $\begin{aligned} & V_{\text {rerata }} \\
&= V_{2}(\mathrm{~V}) \\
&\end{aligned}$ & $\begin{array}{c}\mathrm{n}_{\mathrm{i}} \\
\left(\mathrm{cm}^{-3}\right)\end{array}$ & $\begin{array}{c}\mathrm{J}_{\mathrm{i}} \\
\left(\mathrm{A} / \mathrm{cm}^{2}\right)\end{array}$ & $\begin{array}{c}\mathrm{R} \\
\left(\mathrm{W} / \mathrm{cm}^{2}\right)\end{array}$ \\
\hline 0.6 & 0.00079 & $2.1 \mathrm{E}+16$ & 480 & 360 & 180 & $1.6 \mathrm{E}+09$ & 0.0012 & 0.2 \\
\hline 0.7 & 0.00092 & $2.4 \mathrm{E}+16$ & 525 & 394 & 197 & $1.7 \mathrm{E}+09$ & 0.0014 & 0.3 \\
\hline 0.8 & 0.00105 & $2.8 \mathrm{E}+16$ & 568 & 426 & 213 & $1.9 \mathrm{E}+09$ & 0.0017 & 0.4 \\
\hline 0.9 & 0.00118 & $3.1 \mathrm{E}+16$ & 611 & 458 & 229 & $2.0 \mathrm{E}+09$ & 0.0018 & 0.4 \\
\hline 1 & 0.00132 & $3.5 \mathrm{E}+16$ & 654 & 491 & 245 & $2.2 E+09$ & 0.0021 & 0.5 \\
\hline 2 & 0.00263 & $7.0 \mathrm{E}+16$ & 1048 & 786 & 393 & $3.5 \mathrm{E}+09$ & 0.0041 & 1.6 \\
\hline
\end{tabular}

\section{Kebolehjadian Pembentukan FeN}

Pembentukan ikatan antara $\mathrm{Fe}$ dengan nitrogen sangat beragam, mulai dari $\mathrm{FeN}, \mathrm{Fe}_{2} \mathrm{~N}$ dan $\mathrm{Fe}_{4} \mathrm{~N}$ dan selanjutnya. Dalam makalah ini hanya ditinjau pembentukan FeN saja. berikut :

Dengan melihat tabel besarnya jari-jari atom $\mathrm{Fe}$ dan $\mathrm{N}^{[7,8]}$, maka diperoleh beberapa parameter sebagai

\begin{tabular}{lcccccc} 
Reaksi A + B $\rightarrow$ C + D & $\sigma_{A}(m)$ & $\sigma_{B}(m)$ & $\begin{array}{c}S_{A B} \\
\left(\mathrm{~m}^{2} / p a r\right)\end{array}$ & $M_{A}\left(x_{p}\right)$ & $\begin{array}{c}M_{B} \\
\left(x_{p}\right)\end{array}$ & $k_{B} / \mu_{A B}$ \\
\hline Fe $+\mathrm{N} \rightarrow$ FeN & $1.26 E-10$ & $8.75 E-11$ & $1.43 E-19$ & 56 & $1.40 E+01$ & 726.25
\end{tabular}

dengan $\sigma_{A}(m)$ adalah jari-jari atom $F e, \sigma_{B}(m)$ jari-jari ion $N, S_{A B}\left(m^{2} /\right.$ par) adalah tampang lintang tumbukan atom Fe dengan dengan ion $N, M_{A}$ massa atom $F e$, dan $M_{B}$ massa ion $N$, $k_{B}$ tetapan Boltzmann dan $\mu_{A B}$ massa tereduksi partikel Fe dan ion $\mathrm{N}$.

Dengan menggunakan persamaan (4) sampai (7) maka laju cacah pembentukan FeN dan kecepatan relatif tumbukan sebagai fungsi suhu diperlihatkan pada Gambar 5 dan $6{ }^{[9]}$

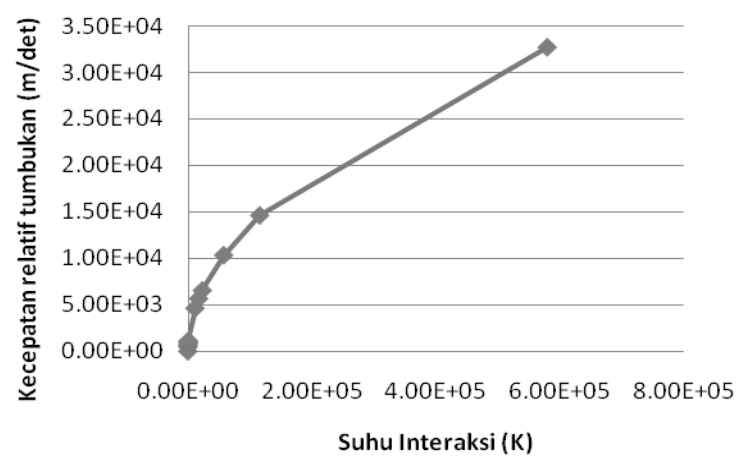

Gambar 5. Kurva kecepatan tumbukan relatif sebagai fungsi suhu

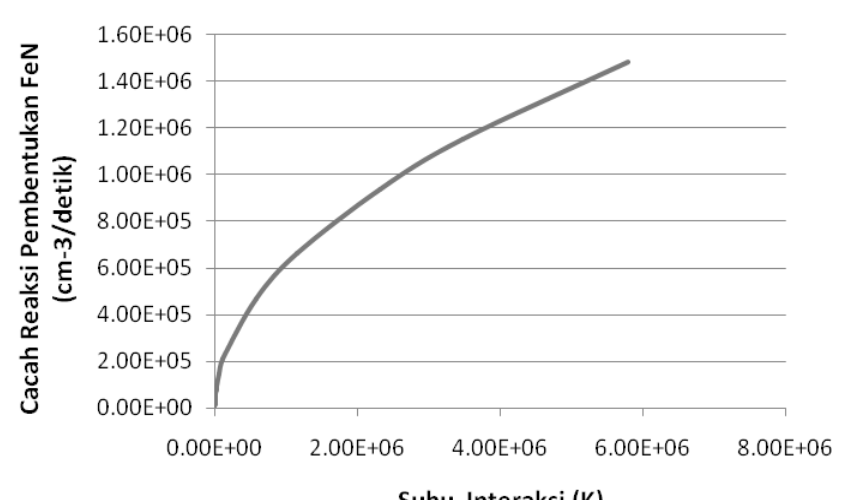

Suhu Interaksi (K)

Gambar 6. Laju cacah pembentukan FeN sebagai fungsi suhu 
Dengan teori tumbukan ini dapat diketahui cukup banyak besaran fisis, seperti kecepatan relatif tumbukan, kebolehjadian tumbukan frekuensi tumbukan dan cacah pembentukan ikatan baru. Seperti ditunjukkan Gambar 5 dan 6., maka tampaklah bahwa untuk suhu semakin tinggi, maka disamping kecepatan relatif tumbukan semakin besar demikian pula jumlah cacah ikatan yang terbentuk.

\section{KESIMPULAN}

Dengan persamaan kekekalan muatan dapatlah diketahui kerapatan ion nitrogen yang menumbuk target, dengan demikian dapat diketahui rapat daya sistem. Besaran rapat daya dan kerapatan ion nitrogen sangat penting untuk memperkirakan panas yang diterima oleh target, dan kebolehjadian pembentukan ikatan baru seperti FeN. Hasil perhitungan menunjukkan bahwa untuk tekanan operasi gas nitrogen dengan jangkau 0,6 sampai 2 torr, maka jangkau kerapatan ion nitrogen yang $1,6-3,510^{9} \mathrm{cacah} / \mathrm{cm}^{3}$, dan jangkau rapat daya $0,2-1,6 \mathrm{~W} / \mathrm{cm}^{2}$. Rentang pembentukan ikatan FeN pada suhu $0 \mathrm{~K}$ sampai sekitar $610^{4} \mathrm{~K}$, adalah dari 0 sampai 1,4 $10^{5}$.

\section{UCAPAN TERIMA KASIH}

Penulis mengucapkan terima kasih yang sebesar-besarnya kepada KPTF dan Redaksi Jurnal Ganendra, yang telah mengoreksi makalah ini sehingga isi makalah menjadi lebih baik, kepada Bapak Ir. Suprapto dan Bapak Drs. Tjipto Sujitno MT, APU yang memberikan tugas untuk membantu beliau dalam rancangan elektroda untuk plasma nitriding. Terima kasih pula kepada Bapak Prof. Sudjatmoko yang telah memberikan tugas untuk membantu beliau dalam program Blockgrant 2010. Terima kasih kepada Bapak Drs Agus Purwadi dan Bapak Drs Aminus Salam, dalam diskusi tentang penelitian plasma. Penelitian ini sepenuhnya dibiayai dari kegiatan penelitian Rancangbangun perangkat nitridasi plasma dengan double chamber untuk perlakuan komponen mesin anggaran DIPA 2010.

\section{DAFTAR PUSTAKA}

1. WIDDI USADA DKK, Perhitungan Parameter Plasma Pada Perancangan Piranti Nitridasi Plasma $20 \mathrm{~kW}$, prosiding PPI Akselerator 2009.

2. ANONIM,Electrical Break-downs Limits for MEMS,ECE234/424 Handout, January,2007

3. ANNA KRAVCCHENKO and HAKAN CANDAN, Glow Discharge, First published on the web: 09.12.2007. The text is based on a lecture given by Zoltan Donko, RISSP Budapest, at the first Gladnet training course in Antwerp Sept. 2007, www.Gladnet.eu

4. C.S. WONG, The Glow Discharge, in Proceedings of 1984 Tropical College on Applied Physics, Laser and Plasma Technology, edited by S. Lee, et al, World Scientific Publish Co. Pte, Ltd, 1985.

5. ANONIM, Collision theory, in http://en.wikipedia.org/wiki/collision_theory.

6. SUPRAPTO, Desain Perangkat Nitridasi Plasma dengan Double Chamber Untuk Perlakuan Komponen Mesin,2009 untuk presentasi rapat koordinasi.

7. Iron in http://en.wikipedia.org/wiki//ron

8. Nitrogen in http://en.wikipedia.org/wiki/Nitrogen

9. WIDDI USADA, Perhitungan Break-down Revisi 2.xls.microsoft excel files, 2009 


\section{LAMPIRAN}

Diagram Alir Perhitungan kerapatan ion nitrogen dan lain lain di daerah pemercepat

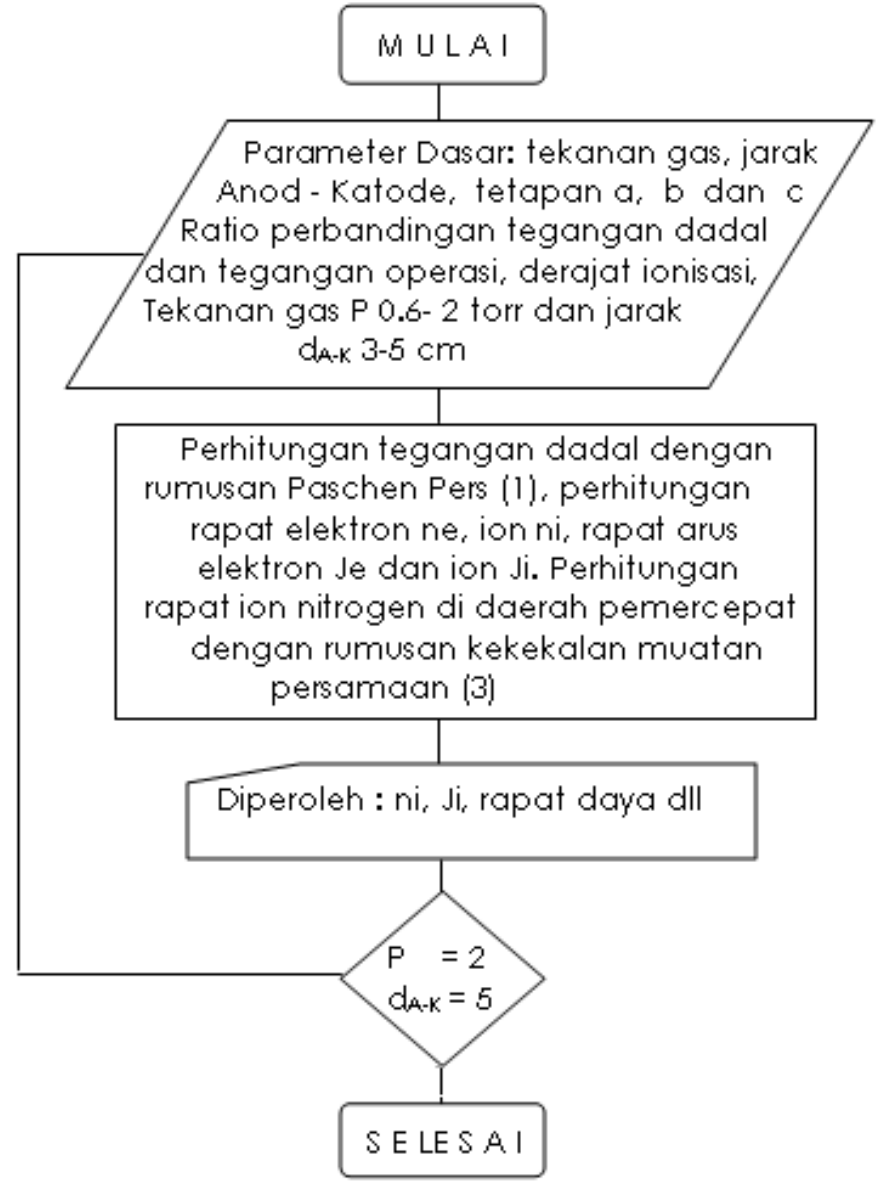

